\title{
Isolation of Anti Solar Compound from Costus Speciosus Leaves
}

\author{
Prasenjit Mitra ${ }^{1}$, Tanaya Ghosh², Prasanta Kumar Mitra ${ }^{3 *}$
}

\begin{abstract}
${ }^{1}$ Department of Biochemistry, All India Institute of Medical Sciences (AIIMS), Basni Industrial Area, MIA 2nd Phase, Basni, Jodhpur, Rajasthan 342005, India

${ }^{2}$ Department of Medical Biotechnology, Sikkim Manipal University, Sikkim Manipal Institute of Medical Sciences, Gangtok, Sikkim, India

${ }^{3}$ Professor \& Head, Department of Medical Biotechnology, Sikkim Manipal University, Sikkim Manipal Institute of Medical Sciences, Gangtok, Sikkim, India
\end{abstract}

DOI: $10.36347 /$ sajp.2020.v09i01.005

| Received: 06.01.2020 | Accepted: 13.01.2020 | Published: 16.01.2020

*Corresponding author: Prasanta Kumar Mitra

\section{Abstract}

\section{Original Research Article}

Ultraviolet (UV) radiation is required by humans for synthesis of vitamin - D in body. Vitamin - D is important for formation and maintenance of bones. Vitamin - D is also involved in different metabolic processes. UV radiation is, therefore, good for humans. But, UV radiation has many bad effects too. Eyes and skins are affected. Prolonged exposure of UV radiation may cause skin cancer and develop cataract. Therefore there is continuous search for anti solar compounds from different sources including plants and herbs. Recently we found that leaves of Costus speciosus (C. speciosus), a leafy green herb having many pharmacological properties, can absorb ultraviolet radiation. Aim of the present work was to isolate the anti solar compound from $C$. speciosus leaves. Leaves of $C$. speciosus were collected, identified by taxonomist and processed for isolation work by standard methodologies. Solvent extraction and acid hydrolysis were done. These were followed by solvent treatment and chromatographic experiments. A compound was crystallized. UV absorption property of the isolated compound was studied. The compound showed maximum ultraviolet absorption at $200 \mathrm{~nm}$. The compound, therefore, may be used in the preparation of sun screen lotion as anti solar compound.

Keywords: Costus speciosus leaves, UV absorbing property, isolation of active compound, sun screen lotion. Copyright @ 2020: This is an open-access article distributed under the terms of the Creative Commons Attribution license which permits unrestricted use, distribution, and reproduction in any medium for non-commercial use (NonCommercial, or CC-BY-NC) provided the original author and source are credited.

\section{INTRODUCTION}

Skin protects body from the external environment. It helps to regulate fluid balance and temperature. Skin also keeps out chemicals and harmful microbes from the body. It offers some protection against sunlight. Stratum corneum, the outermost layer of the skin, retains water to allow it to function. It also protects body from environmental challenge and desiccation. Altered integrity of the Stratum corneum causes transepidermal water loss and makes skin dry [1].

Skin may be damaged by ultra violet radiation. Ultraviolet (UV) radiation are of three types: UV-A, UV-B and UV-C. UV-A, falls under $320-400 \mathrm{~nm}$, is known as black light. UV-B, falls under 280-320 nm, and UV-C, falls under $200-280 \mathrm{~nm}$, are known as erythemal and germicidal respectively. UV-C is dangerous and can cause biological damage to skin and eye. Eventually UV-C radiations are filtered by the ozone layer. So, UV-A and UV-B are now considered the reason of skin damage causing skin cancer [2].
UV radiation comes from sunlight. About $7 \%$ of the sunlight is in the ultraviolet range [3], though a fraction reaches the surface of the earth. UV radiation also generates through the laboratory equipment like biological safety cabinets, trans illuminators, germicidal lamps, lasers and cross linkers. Ultraviolet radiation has numerous bad effects. It destroys disease-fighting white blood cells in humans thereby affects immune system [4]. It can also stimulate genetically determined photo sensitivities and photosensitivity reactions to ingested drugs. Excessive exposure of ultraviolet radiation may cause skin cancer. Squamous cell carcinoma, basal cell carcinoma or malignant melanoma types skin carcinoma may develop. Exposure of ultraviolet radiation is also responsible for formation of cataract.

Efforts are, therefore, going on to search for compounds from different sources which can absorb ultraviolet radiation. Plants are taken as one source. It is reported that many plants contain polyphenols which can absorb ultraviolet radiation [5]. In this context research has been extended in the field of medicinal 
plants. Several medicinal plants like Azadirachta indica, Carica papaya, Aloe vera, Lycopersicon esculantum, Cassia fistula L., Mentha piperita, Oscimum sanctum, Phyllostachys pubescens, Calotropis gigantea L. etc. are now known to possess anti solar activity [6].

C. speciosus (family, Costaceae), is a medicinal plant. The plant has wide range of pharmacological activity [7, 8]. Recently we found that ethanol extract of $C$. speciosus leaves of rainy season can absorb maximum ultraviolet radiation at $200 \mathrm{~nm}$ wave length. Results are under communication. Aim of the present work was to isolate the anti solar compound from $C$. speciosus leaves for its future use.

\section{MATERIAL AND METHODS \\ Plant Material}

Leaves of $C$. speciosus of rainy season (June August) were collected from the local market and authenticated by the experts of the department of Botany of the University of North Bengal, Dist. Darjeeling, West Bengal, India. A voucher specimen (No.SM-MB-011) was kept in the department of Medical Biotechnology, Sikkim Manipal Institute of Medical Sciences of the Sikkim Manipal University, Gangtok, Sikkim, India for future references.

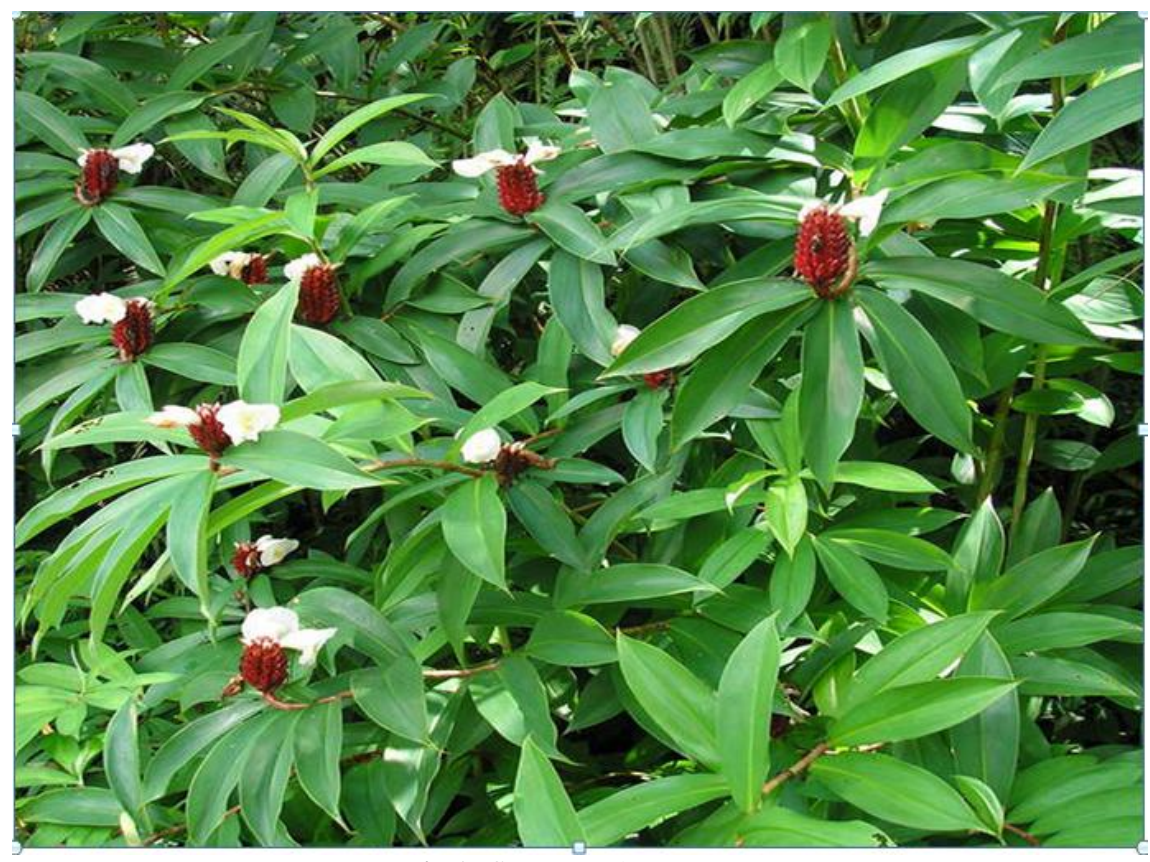

Fig-1: Costus speciosus leaves

\section{Test Drug}

C. speciosus leaves were washed thoroughly under tap followed by distilled water. Leaves were then shed dried and powered. The powder, used as test drug, was stored desiccated at $4{ }^{0} \mathrm{C}$ until further use.

\section{Isolation Work}

This was done by the following scheme. Principles of standard isolation procedures of chemical compounds from plant sources were applied [9, 10].

\section{Chemicals}

Chemicals required for the study were purchased from Merck, Germany and Sigma Chemicals Co., USA as well as from Loba Chem. Lab, Himedia Lab, India. 


\section{Diagrammatic scheme for isolation of a compound from $C$. speciosus leaves}

Powdered leaves of C. speciosus (75 g)

SOLVENT EXTRACTION

Extracted with $500 \mathrm{ml}$ of ethanol for 15 min at $37^{\circ} \mathrm{C}$ in a Soxhlet apparatus. It was then centrifuged. Supernatant collected and evaporated to dryness.

Refluxed with $20 \mathrm{ml}$ of $1(\mathrm{~N}) \mathrm{HCl}$ for $15 \mathrm{~min}$ on a water bath at $100{ }^{\circ} \mathrm{C}$. It was then cooled and centrifuged. Supernatant was evaporated to dryness.

Brown mass

TREATMENT WITH ETHYL ACETATE

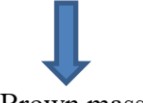

Brown mass

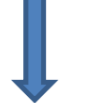

Treated with $70 \mathrm{ml}$ ethyl acetate on a rotary shaker for $15 \mathrm{~min}$. It was then centrifuged. Supernatant was evaporated to dryness.

\section{ALUMINA COLUMN CHROMATOGRAPHY}

Brown mass was extracted with $25 \mathrm{ml}$ of ethanol for $10 \mathrm{~min}$. It was then filtered. With filtrate alumina column chromatography was performed. Elution was done by acetone - ethanol mixture $(50: 50 \mathrm{v} / \mathrm{v})$.

Second band was found active

\section{POLYAMIDE COLUMN CHROMATOGRAPHY}

Eluent of active second band was evaporated to dryness. The dry mass was extracted with $25 \mathrm{ml}$ ethanol for $10 \mathrm{~min}$. It was then filtered. With filtrate polyamide column chromatography was performed. Elution was done by chloroform: ethanol mixture $(40: 60 \mathrm{v} / \mathrm{v})$

Fifth band was active

SILICA GEL G COLUMN CHROMATOGRAPHY

Eluent of active fifth band was evaporated to dryness. The dry mass was extracted with $20 \mathrm{ml}$ ethanol for $10 \mathrm{~min}$. It was then filtered and the filtrate was subjected to silica gel column chromatography using silica gel $\mathrm{G}$ as adsorbent. Elution was done by benzene: ethanol mixture $(60: 40 \mathrm{v} / \mathrm{v})$. Third band was found active

\section{CRYSTALLIZATION}

Eluent of the active third band obtained from the above step was evaporated to dryness. Repeated crystallization was done from Crystals obtained $(6.8 \mathrm{mg})$ chloroform: ethyl acetate $(50: 50, \mathrm{v} / \mathrm{v})$ mixture.

\section{UV absorption property of the isolated compound}

To $10 \mathrm{mg}$ of the isolated compound distilled water $(50 \mathrm{ml})$ was added. The solution was filtered and the filtrate was processed in a spectrophotometer for UV ray absorption at the ranges of $200-400 \mathrm{~nm}$ at 10 nm intervals.

\section{STATISTICAL ANALYSIS}

All experiments were performed in triplicate. Statistical analyses were performed by one-way analysis of variance (ANOVA) followed by Dunnett's multiple comparison test. p-value of $<0.05$ was considered statistically significant [11].

\section{RESULTS}

\section{Isolation of compound}

One compound was isolated from C. speciosus leaves.

\section{UV absorption property of the isolated compound}

Result is shown in Figure-2. The compound isolated from $C$. speciosus leaves absorbed rays in all wave lengths of UV region. Absorptions in respect of wave lengths were, $0.50(400 \mathrm{~nm}), 0.62(350 \mathrm{~nm}), 0.71$ $(300 \mathrm{~nm})$ and $0.90(250 \mathrm{~nm})$. Maximum absorption, however, was noted at $200 \mathrm{~nm}$ (1.6).

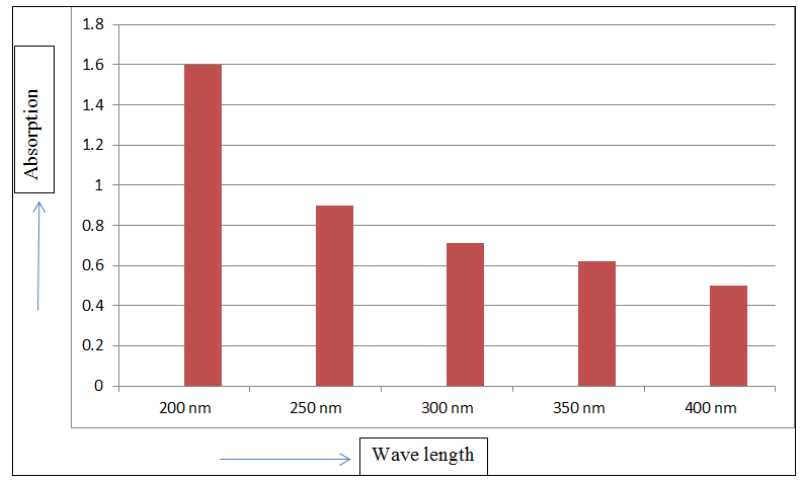

Fig-2: UV radiation absorption by the isolated compound from $C$. speciosus leaves

\section{DISCUSSION}

Basal cell carcinoma, squamous cell carcinoma and cutaneous malignant melanoma are the commonest types of skin cancer. Basal cell carcinoma and squamous cell carcinoma are non-melanoma tumors which are the 5th most commonly occurring cancer in men and women. 4.3 million cases of basal cell carcinoma are diagnosed in the U.S. each year. In fact basal cell carcinoma is the common type of the skin cancer worldwide, but in India most prevalent skin 
cancer is squamous cell carcinoma. Melanoma, on the other hand, is the 19th most commonly occurring cancer in men and women. Three lacs new cases of melanoma were reported in 2018. In 2018 Denmark had the highest rate of melanoma in women followed by New Zealand. It is now known that incidence of skin cancers has been increasing since the last few decades worldwide [12].

According to the American Cancer Society exposure to ultraviolet (UV) radiation is the main factor that causes skin cells to become cancer cells. There is experimental evidence that UV radiation can cause squamous cell carcinoma and melanoma in animal models. It is reported that about $95 \%$ of melanoma and $99 \%$ of non-melanoma skin cancers in humans are associated with exposure to UV radiation from the sun [13].

Efforts were thereby started to search the blockers which can absorb UV radiation of sun. Physical sun blockers and Chemical sun blockers were developed. In physical sun blockers zinc oxide and titanium dioxide are used. These compounds could protect the body both from UVA and UVB rays. Chemical sun blockers contain organic compounds like octinoxate, octisalate, oxybenzone, avobenzone etc. By creating a chemical reaction these compounds could change UV rays into heat thereby diminish the bad effects of UV radiation. In addition, foods like red grapes, watermelons, carrots, green tea, pomegranates, tomatoes, turmeric, citrus fruits, strawberries, almonds, leafy greens etc. can boost natural sun protection effect [14].

C. speciosus is an edible leafy green of Sikkim Himalayas. The plant has different names. In Bengali and Hindi $C$. speciosus is known as keu. The plant has several other names also viz. Kashmeeramu (Telegu), Kembuka (Sanskrit), Paskarmula (Guajarati), Tara (Assam), Channakoova (Malayalam), Spiral flag (English Kostam (Tamil), etc [15].

Since long C. speciosus is used in traditional medicine as expectorant, purgative, anthelmintic and stimulant. It is also used in the treatments of skin diseases, urinary diseases, cough and cold, pneumonia, dropsy, fever, bronchial asthma, rheumatism, diarrhea, dysentery, dyspepsia, jaundice, eye and ear infections as well as in snake bite cases [16]. The plant has many pharmacological activities including anti diabetic, anti oxidant, anti allergic, anti gastric ulcer, anti microbial, anti cancer, anti inflammatory, gastro protective and hepato protective activities $[7,8]$.

Jeffrey et al., found occurrence of UVA- and UVB-absorbing compounds like Shinorme, porphyra334, mycosporine-glycine, asterina-330, palythine etc. in 152 species (206 strains) of marine microalgae [17]. Recently we have observed UV absorption property of leaves of $C$. speciosus of Sikkim Himalayas and maximum absorption was found in ethanol extract of the plant leaves of rainy season. In this study we have isolated the one compound from the plant leaves. The compound can absorb rays in all wave length of UV region but maximum absorption was noted at $200 \mathrm{~nm}$. The compound now needs characterization. Presently work is going on in our laboratory in this direction.

\section{CONCLUSION}

In the present study we found UV radiation absorption property of the isolated compound from $C$. speciosus leaves. The compound may be used in future in preparation of sun screen lotion to protect humans from UV radiation.

\section{ACKNOWLEDGEMENTS}

We gratefully acknowledge the cooperation of taxonomists of the department of Botany, University of North Bengal, Siliguri, Dist. Darjeeling, West Bengal for identification of $C$. speciosus leaves.

\section{Conflict of interest: Nil}

\section{REFERENCES}

1. Rawlings AV, Scott IR, Harding CR, Bowser PA. Stratum corneum moisturization at the molecular level. Journal Investig Dermatol. 1994;103:731740 .

2. Urbach F. The historical aspects of sunscreens. Journal Photochem Photobio. 2001; 64: 99-104.

3. Nicholson WL, Schuerger AC, Setlow P. The Solar UV Environment and Bacterial Spore UV Resistance: Considerations for Earth-to-Mars Transport by Natural Processes and Human Spaceflight. Mutat Res. 2005; 571 (1-2):249-264.

4. MacKie RM. Effects of Ultraviolet Radiation on Human Health. Radiation Protection Dosimetry. 2000; 91(1-3):15-18.

5. Rong T. Chemistry and Biochemistry of Dietary Polyphenols. Nutrients. 2010; 2:1231-1246.

6. Gupta D. Absorbing Properties of Some Plant Derived Extracts. Research Journal of Chemical and Environmental Sciences. 2013;1(2):34-36.

7. Bhattacharya SK, Parik AK, Debnath, PK, Pandey, $\mathrm{VB}$, Neogy, NC. Anticholinesterase activity activity of Costus speciosus alkaloids. Indian Journal Pharmacol. 1972; 4:178-178.

8. El-Far AH, Shaheen HM, Alsenosy AW, El-Sayed YS, Al Jaouni SK, Mousa SA. Costus speciosus: Traditional Uses, Phytochemistry, and Therapeutic Potentials. Pharmacognosy Reviews. 2018 Jan 1;12(23):120-127.

9. Cannell RJP. Natural Products Isolation, New Jersey, Human Press Inc. 1998;165-208.

10. Li HB, Jiang Y, Chen F. Separation methods used for Scutellaria baicalensis active components. Journal Chromatography. 2004;8(12):277-290. 
11. Bliss CI. Statistics in biology, Statistical methods for research in the natural Sciences, Vol. 1, McGraw Hill Book Company, NY. 1967: 558.

12. Saumya P. Nonmelanoma skin cancer in india: Current scenario. Indian Journal Dermatol. 2010:55(4):373-8

13. Armstrong BK, Kricker A. The epidemiology of UV induced skin cancer. Journal of photochemistry and photobiology B: Biology. 2001 Oct 1;63(1-3):8-18.

14. Radhika B, Samreen N, Ramya N, Nooreen N. Evaluation of antisolar activity of Hibiscus hirtus linn. J.Bio.Innov. 2019; 8(2):127-133.
15. Swati S, Agarwal P. Kebuka (Costus Speciosus): A critical review. World J Pharm Pharm Sci. 2015; 4: 421-31.

16. Srivastava Shruti, Singh Pradeep, Mishra Garima, Jha KK, Khosa RL. Costus speciosus (Keukand): A review. Der Pharmacia Sinica. 2011; 2 (1) : 118128.

17. Jeffrey SW, Mac Tavish HS, Dunlap WC, Visk M, Groenewoud K. Occurrence of UVA- and UVBabsorbing compounds in 152 species (206 strains) of marine microalgae. Marine Ecology Progress Series. 1999;189: 35-51. 